A section for the review of books is a regular feature of Landscape Journal. The opinions and ideas expressed in the reviews are those of the reviewers and do not necessarily depict the views of the Journal's editors or the Council of Educators in Landscape Architecture.

Suggestions for books to be reviewed are always welcome, as are comments regarding the reviews published. All correspondence should be sent to the Book Review editor:

Donna L Erickson, Book Review Editor

Landscape Architecture Program

School of Natural Resources and Environment

University of Michigan

Ann Arbor, MI 48109-1115

e-mail:dle@umich.edu

\section{MIDWESTERN LANDSCAPE ARCHITECTURE}

edited by William $\mathrm{H}$. Tishler. Urbana: University of Illinois Press, 2000. ix + 256 pages, photographs, $\$ 37.50$,

clothbound.

ISBN 0-252-02593-8

Reviewed by Heidi Hohmann

$\mathrm{S}$ andwiched between the tradition of the East Coast and the innovation of the West Coast, the Midwest has long been considered physical and intellectual flyover country. This is certainly true in landscape architectural practice and history. Although most practitioners can cite a raft of significant projects, both current and historic, hailing from either coast, ask those practitioners to name a groundbreaking project in the Midwest, and they go silent. Midwestern Landscape Architecture takes on the ambitious task of changing these parochial perceptions, hoping to "foster a better understanding of the origins of landscape architecture in the American Midwest and the contributions this profession has made to the interaction of people with their environment in the region" (p. 2).

To a large extent Midwestern Landscape Architecture succeeds in this endeavor, compiling in a single volume an immense amount of information on largely undocumented designers. Thirteen chapters each describe the life and work of a land- scape architect who practiced in the Midwest. Written by a talented cast of landscape scholars, the chapters are well researched, well documented, and well written. Highly readable, Midwestern Landscape Architecture will be a useful reference for students and, with its many pages of detailed footnotes, for future researchers. For landscape architectural history buffs, the book is a veritable feast. New facts about little known designs and designers are illuminated on almost every page. Miriam Rutz paints a bright and powerful portrait of the virtually unknown Genevieve Gillette, who advanced from an early position as Jens Jensen's secretary to become one of Michigan's foremost parks advocates. Arnold Alanen brings Ohio-born Elbert Peets out of Werner Hegemann's shadow with an exposition of Peets's design for Greendale, Wisconsin. And it is a relief to see that Kurt Culbertson has finally brought to light a significant text on the often-overlooked work of George Kessler. Perhaps best of all is Christopher Vernon's wonderful piece of scholarship on horticulturist and writer Wilhelm Miller. This chapter not only documents Miller as a charismatic salesman preaching an inspirational doctrine of Midwestern landscape design, but also explicates the origins and meanings of the terms "Prairie Style," "Prairie Spirit," and "Prairie School." Vernon's definitive explication of these terms should help discontinue their use as a blanket description of midwestern regional design.

Other chapters present critical reassessments of Midwestern work by better-known designers. These chapters do less to define midwestern landscape architecture than they do to chart its origins at the national level. Reuben Rainey places William Le Baron Jenney's Central Park in Chicago squarely in the tradition of an eastern, "Olmstedian concept of an urban park"(p. 66). His evaluation is backed up by terrific analytical drawings. Victoria Ranney's assessment of Olmsted's Chicago work also clarifies that "Olmsted's vision was not so much regional as national" (p. 55). Yet her deft re-evaluation of Olmsted's use of water as an expression of the region's abundant water resources is a new twist on earlier interpretations of Olmsted in the Midwest. Lance Neckar similarly revisits the work of Warren Manning. Like Ranney, Neckar clearly has no illusions that Manning was a Midwestern landscape architect, stating that he "never adopted a comprehensive regional design aesthetic" (p. 151). Instead, Neckar argues that Manning's midwestern work was an incubator for his ideas about a progressive, resource-based landscape architecture, ideas he would later apply at a national scale.

In the midst of all this insight, there are also a few clinkers. William 


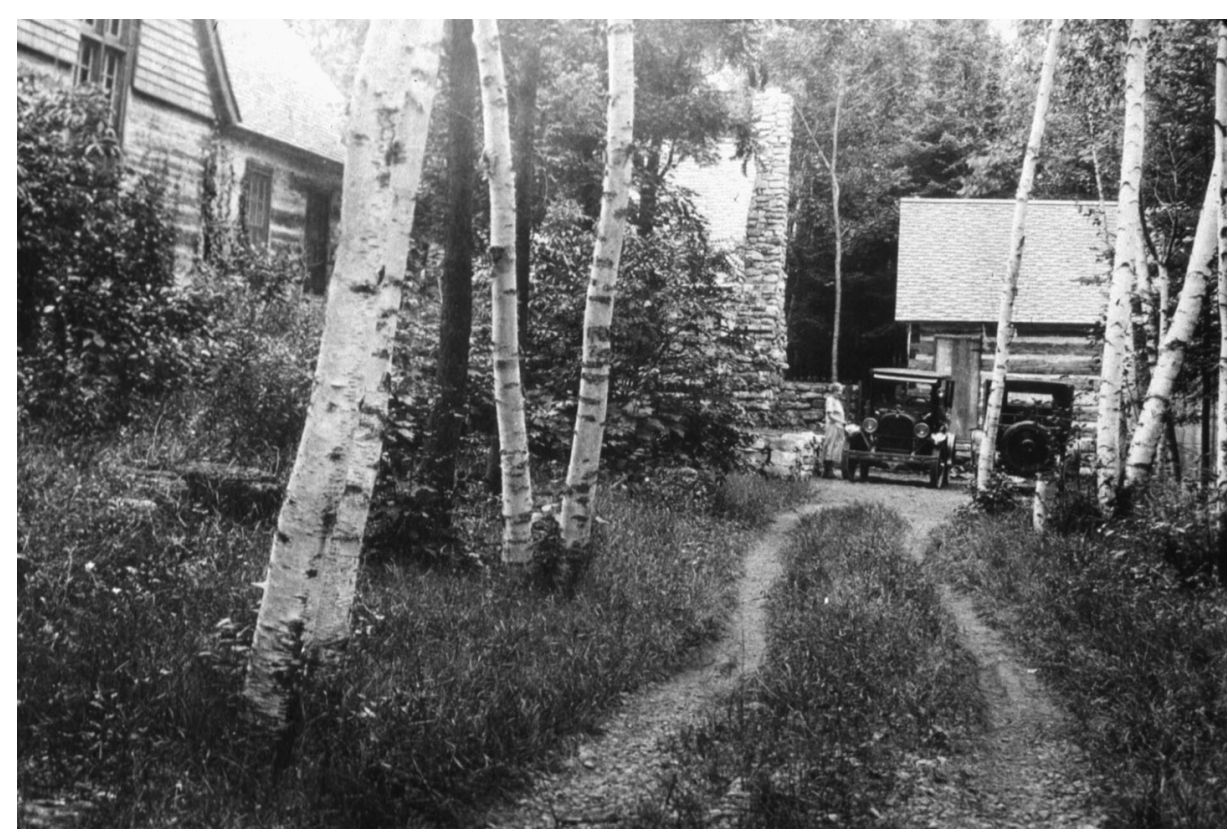

్ㅠㅇ

T⿱宀 Frothers wanders from the Midwestern task at hand, dissolving into an unenlightening comparison of forGial and informal design in Chicago garks. And by wrapping up with Pamela Filzen's chapter on Annette ㄱotoyt Flanders, the book ends with an ưffortunate whimper. Although it is ăd well researched as any other chapr, and although the brief hints of Flanders's Modernist work are inựiguing, Flanders's predominantly aesidential designs are less innovative 글 influential than the public work atured in other chapters. Were it Ф્ّot for Rutz's dynamic chapter on Ëillette and Kurt Culbertson's short et striking description of Eda Sutermeister in Kessler's office, readers might simply write this chapter off as gender-based tokenism.

But these are minor faults in an exemplary collection. What is disappointing about Midwestern Landscape Architecture is that the book remains a collection. The chapters, despite their chronological arrangement, exist as disconnected research efforts. It is true that many of the same places-Chicago's Humboldt Park, for example-appear in multiple chapters. But the book does not address the issues raised by the juxtaposition of the thirteen essays-issues such as how Jenney's and Jensen's works interact in Humboldt Park, why Cleveland's and Kessler's Midwestern designs are similar, or whether designers educated in the East designed differently than those educated in the Midwest. Because such issues are never examined, the whole of the book never becomes greater than the sum of its parts.

The blame for this shortcoming lies with the introduction. Instead of examining the conceptual linkages between chapters, the introduction rehashes old history, dwelling on a poetic but worn-out development of the "Prairie Style" by O.C. Simonds, Jensen, and Miller. What a missed opportunity, given the rest of the book's fresh content. How much more insightful it would have been to speak of changing viewpoints about the prairie, to contrast Olmsted's 1868 description of the Midwest as "low, flat, miry and forlorn" with Miller's 1912 description of it as "the runway of the winds and ideas," and to speculate on the reasons for these changing perspectives (pp. 47, 182). Tishler might have considered the Midwest as the practice ground for the "insider" and the "outsider," to compare the work of designers who practiced in the Midwest but lived elsewhere, with those who were born in or adopted the prairie as their home, or to ask some hard questions about the assumptions this book makes, such as, What really is "Midwestern landscape architecture?" How does a designer become a "Midwestern landscape architect?" Is regionalism, however compelling, a valid lens for explicating landscape architectural history?

These unasked questions mar an otherwise transcendent effort. And they point out a disturbing trend in landscape history, where assemblage masquerades as historiography. The source of this trend is obvious and understandable. Confronted with an appalling lack of baseline information in landscape history, the field has rushed to amass a body of knowledge and make it public. This instinct has resulted in a decade of useful, encyclopedic books like American Landscape Architecture (Tishler 1989), The Architecture of Western Gardens (Mosser and Teyssot 1991), and the more recent Pioneers of American Landscape Design (Birnbaum and Karson 2000). This instinct has also created inventories of historic landscapes and produced catalogs of landscape records, efforts to capture and record historic information before it vanishes. The work encompassed in these labors is important and should not be demeaned. But it is not the only work.

History can't just be collected; it needs to be constructed. To truly build a landscape architectural history (let alone a midwestern landscape architectural history) landscape scholars need to ask, and begin to answer, the larger questions. The field must seek out the conceptual glue that sticks building-block research together. If scholars do not initiate this inquiry, landscape architecture has no history-it has only vignettes.

Landscape history is no longer in its infancy. The field cannot continue to discover data while ignoring the broader questions that define the overall discipline. Otherwise land- 
scape history, not the Midwest, will be flyover country.

Heidi Hohmann is Assistant Professor of Landscape Architecture at Iowa State University in Ames.

\section{ON THE PLAZA: THE POLITICS} OF PUBLIC SPACE AND CULTURE

by Setha Low. Austin: University of Texas Press, 2000. xx +274 pages, illustrations, photographs, tables, maps, plans, index, $\$ 40.00$ clothbound ; $\$ 18.00$ paperback. ISBN 0-292-74713-6 (cloth) ISBN 0-292-74714-4 (paperback)

\section{Reviewed by Kristine Miller}

$\mathrm{T}$ he discipline of landscape architecture considers itself to be engaged in improving public life. However, there is a lack of writing that critically analyzes the social and political implications of design, the management and redevelopment of public space, and the role of the designer in these activities. Modifications to public spaces concretize assumptions about what a community values, what activities it deems suitable, and what version of itself it wants to promote. Setha Low's On the Plaza is an important contribution to these discussions. It presents the designer as an agent of physical changes that have broad and complex implications. Low's work is a densely woven study of two Costa Rican plazas that reveals the connections among people, physical space, politics, and culture. She employs multiple perspectives and research methods in her work. Trained as an anthropologist, Low is currently a professor in the $\mathrm{PhD}$ programs of Anthropology and Environmental Psychology at the City University of New York. Prior to teaching at CUNY, Low was recruited by Ian McHarg to teach at the University of Pennslyvania's Department of Landscape Architecture and Urban Planning. During the fourteen years she was at Penn, Low taught a wide breadth of courses including: the ecology of health, social and behavioral research methods, design studio, housing and culture, cultural landscapes, and medical anthropology.

On the Plaza brings together Low's research on two sites in San José over the course of twenty-five years. The sites Low examines, Plaza de la Cultura and Parque Central, provide excellent case studies of Central American public space. With every chapter, Low employs different research approaches over varying scales of time and space including ethnography, participant observation, personal narrative, and historiography. Low describes her approach as one that spatializes culture: "By spatialize, I mean: to locate-physically, historically, and conceptuallysocial relations and social practice in space"(p. 127) The resulting body of work is the kind of thick sitegrounded iterative history that is lacking in a majority of texts on design and public space.

Low introduces Parque Central and Plaza de la Cultura through a set of field notes, the earliest from 1985, the latest from 1997. In these notes the plazas are described in Low's words as participant observer: "Young people lounge on the kiosk, girls and boys separately watching each other. Couples with children wrapped up as sleepy bundles walk by. The police also wander across the kiosk surveying the passersby" (p. 11). Low's notes set out the issues that she will address throughout the course of the book: the ways in which people interact on the plazas in the course of their daily lives; how they react when design and management changes are made to these spaces; and how the plazas become the site (literally and figuratively) of public debate regarding issues of culture and politics.

The subsequent chapters are divided into sections that examine various issues: the history of the Central American plaza; the plazas of Costa Rica; political issues related to plaza development; and the ways in which culture, memory, literature, and daily life create competing individual meanings for public spaces. Each section reveals issues of importance to the discipline of landscape architecture. For example, "Part II Histories," fills a significant gap in landscape architectural history by analyzing the South American plaza and its colonial and indigenous influences. Based on an evaluation of content alone, these chapters are a significant contribution to the history of public space. As Low indicates, Latin American sites receive little or no discussion in landscape architectural history courses and texts. Architectural histories that describe these spaces concern themselves with how these plazas relate to Spanish precedents and are physical evidence of colonial rule. Furthermore, as Low notes, these architectural descriptions often present indigenous people as passive recipients of colonial culture, when other fields such as anthropology and religious studies have previously identified the synchronous nature of Central American culture. Low argues that our knowledge of the Central American plaza will be limited "until we uncover how each was designed and built, by whom, and for what purpose. The politics of indigenous as well as the colonial plazas must be grounded in the study of their use" (p. 122). By examining the complex histories of specific Central American plazas, Low represents these plazas as examples of political and cultural contestation.

An important part of Low's work is the set of theoretical constructs she develops and her skill in clearly discussing complex ideas. For example, Low describes the importance to her research of the paired concepts of production space vs. construction of space. She defines the social production of space as the "social, economic, ideological, and technological" factors that "result, or seek to result, in the physical creation of the material setting" (p. 128). Production of public space may be familiar as a Marxist idea indicating that public spaces are the resultants of hegemonic economic and political conditions and that by studying these spaces as kinds of artifacts, we can learn about the systems that 
produced them. In contrast, Low defines social construction of space as the transformation of spaces or material settings into "scenes and actions that convey meaning" as a result of "people's exchanges, memories, images, and daily use of the material setting" (p. 128). Construction of public space refers to the ways in which people build an understanding of and relationship to a particular place through their daily interactions in and on that space. These daily interactions, memories, stories, etc. constitute a place's meaning for an individual. Low cites the work of French social theorist Henri Lefebvre in the development of the idea of construction of space.

Understanding issues of culture and politics through daily-lived experience, Low argues, is also an imporEant concept within anthropology and, I would argue, has important 要plications for landscape architecGre. Because the social construction of public space is developed through undividual experience it leads to conElicts when individuals or groups hold views of the space that are incompatible. Like art critics Rosalyn Eeutsche and Donald Crimp, Low sées the role of public space as the sitte of ongoing conflict and disagreeQ Eूfy. Furthermore, it is not only local residents who construct public space, Spatial meanings are actively manipت्ञlated by the city and the state to repsent diverse political and economic 范endas"(p. 239). The social producFion and construction of public opaces is ongoing and iterative. Certain values are concretized by groups or individuals through new physical forms or management strategies. These values are then contested in and on public space through demonstrations, vandalism, and public debate. Clearly, Low's work raises issues that must be addressed. For example: What political and social agendas does the work of landscape architects at certain sites and at certain times serve to concretize? Are they values that designers believe will fulfill the profession's goal of improving public life?

On the Plaza indicates the direction in which discussions of public space are moving outside of the discipline of landscape architecture. Researchers, including social historians, art critics, anthropologists, and political theorists are currently addressing these issues. Low brings this work to the designer's doorstep. It is important for us to carefully examine her work, and consider how it might point to changes in the way we practice, teach, and study.

Kristine Miller is Assistant Professor of Landscape Architecture at the University of Minnesota, Minneapolis.

\section{THE LIVING LANDSCAPE. AN \\ ECOLOGICAL APPROACH TO}

LANDSCAPE PLANNING, 2nd ed.

by Frederick R. Steiner. New York: McGraw-Hill, Inc., 2000. 477 pages, $\$ 59.95$ clothbound. ISBN 0-07-079398-0

Reviewed by Danilo Palazzo

$\mathrm{T}$ his is the second edition of The Living Landscape, coming nine years after the first. The book was first published in 1991, and received an ASLA Merit Award for Communications in 1993. It was translated into Italian in 1994, after which it was very well received among scholars and students of planning, as well as in the schools of architecture throughout Italy.

The first obvious difference between the two editions is the publishing series. The first did not form part of a series while the second is now in the McGraw-Hill "Professional Architecture" series. This shift means a lot to me. The Professional Architecture series is devoted to giving helpful tools to practitioners who are in the field. Planners, planning officials, administrators, community-based association members, are directly called to plan. In other words, and as the author says, planning is "a philosophy for organizing actions that enable people to predict and visualize the future of any land area" (p. xiv).
Planning, as the preface to the second edition clearly points out, deals also with sustainability and sustainable development, which means "meet the needs of the present without compromising the ability of future generations to meet their own needs" (p. xi). The Living Landscape provides a very wide set of how-to and whyto-do-it instructions, where-to-keep information, and best practices examples to learn from, organized around an eleven-step Ecological Planning Model. I consider The Living Landscape a refined, highlevel professional handbook devoted to enhancing the toolbox of any present or future planning practitioners.

The Living Landscape brings to mind a book with a very similar title authored by Garret Eckbo, published in the early 1950s. The book is Landscape for Living (1950, New York: Duell, Sloan \& Pearce) and, according to the author's book description: "it is a why-to-do-it book, not a how-to-doit book. America is brimming with know-how. We can make anything, build anything, do anything. But still our cities are sordid, messy, and unhealthful, our countryside riddled with erosion. It is the know-why that is missing, understanding why we do it before we do it. That is called planning (and design)" (Eckbo 1950, p. 60). Frederick Steiner's book consists of a deep evolution within the borders defined by this thought. There is, indeed, a big gap between a landscape that could be lived and livable (in Eckbo's version), and a landscape that is alive for itself, for us, and for future generations (in Steiner's version). In the decades between the two books this gap has been filled, when considering the mainstream, with the ecological planning of the 1960s, the environmental decade of the 1970s, the Geographical Information Systems (GIS) revolution and the (re)foundation of landscape ecology in the 1980s, and, eventually, the 1990s: the so-called turnaround decade. Steiner is at the same time a result, a catalyst, and a protagonist of this long period. The Living Landscape is a book that contains elements of this long and compelling evolution. 
The second edition of The Living Landscape, as was the first, is built around a scheme of eleven steps called Ecological Planning Method briefly presented in the first chapter and used as a step-by-step pattern to guide readers into the organization of a planning process. The Ecological Planning Method is a framework for presenting information to decisionmakers, and to display "a common language, a common method among all those concerned about social equity and ecological parity" (p. 9). The approach to planning presented by Steiner is innovative for two reasons. The first is the incorporation of ecology in planning - briefly "the use of biophysical and socio-cultural information to suggest opportunities and constraints for decision making about the use of the landscape" (pp. $9-10$ ). The second reason is the author's stress on the citizen's involvement in almost every step of his method. These two issues, even if they are the prime themes of the book, are prudently embedded into the body of the full text. Ecology and citizen involvement are the leitmotif of the entire book which is composed of a precise combination of techniques and tools presentation, useful references to literature, light-but effective-revocations of the theoretical frameworks on the issues, and application examples deriving from real plans or projects.

The eleven-step Ecological Planning Model goes from the identification of problems and opportunities (step 1) and the establishment of goals (step 2) to inventories and analysis at regional (step 3) and local level (step 4). It proceeds with the realization of detailed studies (step 5) and the definition of planning concepts (step 6). The landscape plan (step 7) follows and it is directly assessed and criticized by citizens (step 8 ), who are involved and educated along the whole process-phasing. Design exploration (step 9) comes next and the study of the implementation of the plan and projects (step 10) precedes the administration (step 11) that is the last step of the model. The Ecological Planning Model is linear in its descriptions (the book chapters-excluding the introduc- tion and the conclusion-are devoted to deepening every step, with some minor exceptions), but the steps are strongly interactive. In the graphic scheme of the model (p. 11), solid and dashed arrows between the steps emphasize the necessity and the opportunity of feedback and retroactions in order to monitor the previous results.

Citizen involvement is the center of the model. Almost every step is addressed to inhabitants and a systematic educational and citizen involvement effort occurs throughout the process. The model, between the last step-administration-and the first-problem and/or opportunity identification-, presents a dashed arrow in order to accentuate the problems and opportunities facing the region and the goals addressed that may be altered by time, occurrences, and circumstances.

Compared to the first edition, the structure of the Ecological Planning Model and of the book contents remains unchanged in the second, but the book has some 120 more pages. Graphic design of tables and figures has been enhanced-a fourcolor page section was added to present the GIS maps of the Desert View Tri-Villages Area (Arizona) and of the Camp Pendleton study area (California), two of the many new examples used throughout the entire book. New photographs, most of them by Steiner, follow the entire text. Sources and references have been updated, including recent books and articles on the matters. New examples, as mentioned above, have been included in this edition to present more recent application of techniques and tools explained and illustrated in the text. The glossary, one of the many useful tools of the book, has been enlarged with forty-six new entries, bringing the total to 350 .

The Living Landscape gives planners (present and future) tools and explanations, but it also gives them the weight of responsibility. As Steiner says: "Planning gives people the ability to link actions on specific parcels of land to larger regional systems. It is up to us to plan with vision. Our responsibility is to retain what we treasure, because we are merely guests on these spaces of the Earth that we inhabit. We should leave good impressions about our visit". Dr. Danilo Palazzo is Research Professor of Urban Planning in the Dipartimento di Architettura e Pianificazione at Politecnico di Milano in Italy.

\section{THE AMERICAN PLANNING TRADITION: CULTURE AND POLICY}

edited by Robert Fishman. Washington, D. C.: The Woodrow Wilson Center Press, 2000. ix +328 pages, $\$ 24.95$ paperback. ISBN 0-943875-95-X

Reviewed by Patricia L. Machemer

$\mathrm{T}$ his book on American planning presents a broad look at urban and regional planning issues and concepts, with both a historical and contemporary perspective. The book refers to "traditional" planning, and presents a historical view of land planning in the United States. Additionally, it makes a connection to contemporary planning and stresses the importance of learning from our planning predecessors of the nineteenth and twentieth centuries. The contributors to this book do an excellent job in making connections between urban planning issues of yesterday and contemporary urban issues that American cities and regions are presently facing. Furthermore, the book gives a historic look at the cultural and political context that influenced, shaped, and formed the framework from which today's planners must address today's land use issues.

This book is a multidisciplinary effort resulting in contributions that cover a variety of topics including: private property; political structure at the federal, state, regional, and local levels; linkages between geographic areas, between interests groups, and between public and private sectors; and urban issues such 
as racism, environmental quality, renewal, and economic development. The contributors are Carl J. Abbott, Alan Brinkley, Robert Fishman, Arnold R. Hirsch, Michael J. Lacey, Judith A. Martin, Anne Whiston Spirn, John L. Thomas, Sam Bass Warner, Jr., Margaret Weir, and James L. Wescoat Jr.

The book begins with an introduction which presents an overview of traditional American planning and how it shaped urban spaces, including the tradition's origins and uniquely American characteristics. After the introductory chapter, the book is structured around three sections. In the first section, Two Traditions, the authors present two approaches to planning, one that places an emphasis on the middle ground - the land located between Errban centers and the wildernessand one that provides an overview of 莿e metropolitan tradition as an apFroach for achieving both economic and cultural success. Both chapters in this section recognize that past regional and metropolitan approaches hुave utility today as land managers ând planners address current urban Grisis. The second section, The Quest or National Planning, discusses and \&ิnalyzes centralized planning. While 围ost of chapters in this section share a commonality of scale at the naน̊onal level, one chapter utilizes a reछํ. Dु̃espite this difference in scale, all (he chapters in this section form a coEerent whole in that they explore poFtical and social structures, alliances Fnd conflicts in addressing planning goals and objectives. This section includes discussions on the American political structure, principles of federalism, efforts at national planning, and the watershed as a context for regional planning. Tangible examples of national planning efforts are provided, namely the National Resources Planning Board and the $\mathrm{Na}$ tional Land-Use Planning Act. The third section, Recreating the "Commons": A Local Experience, presents four case studies: New Orleans (1947-1968), Portland (since 1970), Chicago (1972-1990), and Boston. The common thread that connects all the chapters of varying themes, each based on the specific city's urban issues, is the ability of each contributor to place his or her topic within a historic context including social, economic, and political dimensions.

While the book appears to outline examples of American planning setbacks, e.g., the elimination of Congressional funds for the National Resources Planning Board, and the failure to pass National Land Use Planning Act, it presents these failures in a historic context, discussing the political, social, and economic dimensions, and suggests how these failures entail threads of success that may be utilized to address current urban issues and perhaps lead to future successes. This book is about lessons learned. It purports that not only can contemporary land planners learn from planning successes, such as the work of Clarence Stein, Frederick Olmsted, Lewis Mumford, Benton MacKaye, Ian McHarg, Andres Duany and Elizabeth Plater-Zyberk, to name just a few who are addressed in the book, they can also advance their thinking by examining planning failures. Rather than simply emphasizing lessons learned from successes, this book stresses learning from the failures, dating back into the earlynineteenth century. These lessons, both from successes and failures, can assist in shaping, visioning, and planning urban and regional areas. The final chapter written by Anne Whiston Sprin emphasizes the necessity of visioning for the future. In this way the book is structured well, leaving us with a chapter that holds promise for planning.

Given its multidisciplinary origins, this book would appeal to a wide range of readers, including those interested in city, urban, and regional planning, as well as urban history, cultural geography, and landscape architecture. Endnotes are comprehensive and may provide a basis for further more detailed investigation on specific urban planning topics and themes. The book contains a number of figures that illus- trate urban and metropolitan concepts, designs and patterns, and photographic perspectives on the resultant urban spaces. While the book includes these graphics, primarily as center plates, additional graphics and maps illustrating the regions, cities, districts, and neighborhoods would assist readers in understanding the concepts presented in the text.

Patricia L. Machemer is Assistant Professor in the Landscape Architecture Program at Michigan State University.

\section{HEALING GARDENS: THERAPEUTIC BENEFITS AND DESIGN RECOMMENDATIONS}

edited by Clare Cooper Marcus and Marni Barnes. New York: John Wiley \& Sons, Inc., 1999. x+610 pp., plates, illustrations, maps, $\$ 85.00$

clothbound.

ISBN: 0471192031

Reviewed by Joanne Westphal

1 ealing Gardens: Therapeuommendations is a comprehensive examination of existing garden areas that are affiliated with a variety of health care delivery institutions worldwide. As such, it presents one of the most complete and current overviews of outdoor designed space for hospital settings today.

The book begins with an introductory chapter to the notion of "healing gardens" and follows with a second chapter that describes the theoretical and scientific underpinnings of the idea that health is derived from natural spaces. This type of organization allows two important sets of information to be presented. In the first chapter, the reader garners a historical perspective on the subject; it is here that the editors are permitted to explain their broad and dynamic concept of "healing" within the past and present confines of institutional health care delivery. In the second chapter, researcher Roger Ulrich outlines the theory and research that currently supports and/or is driving scientific work relating to the 
benefits of garden areas to various user groups. The importance of this latter chapter cannot be overstated; it provides the theoretical framework for linking place, stress, and human health/illness. In the subsequent chapters, editors Clare Cooper Marcus, Marni Barnes, and guest writers present an exhaustive array of information on the layout and details surrounding gardens that have been designed for patients with special medical needs-acute care, psychiatric patients, pediatric patients, nursing home residents, patients with Alzheimer's dementia, and hospice patients. In each chapter, case study materials are presented on a variety of garden areas that serve the respective patient populations, including advantages and disadvantages of each designed area. At the end of each chapter, design guidelines are provided for gardens in nursing homes, hospice facilities, children's gardens, psychiatric hospitals, and acute care settings based on the case study materials. The book concludes with a practical chapter on soliciting and solidifying institutional support for creating and maintaining garden areas in health care facilities. It finishes with an excellent chapter by Terry Hartig and the editors on the unfinished business of research and post-construction evaluation that is needed to strengthen both the art and science of therapeutic site design.

The book provides important insight into the unique demands that medical settings create for designers. Unlike other design arenas (e.g., parks, residential, public plazas), the predominant users of "healing gardens" are in hospital settings because they are seriously ill (too ill to be treated in a home environment). Therefore, a whole set of new knowledge is needed to effectively design for these patient groups; ethical issues relating to privacy and functional utility, along with safety concerns also are a part of the medical setting. These facts, when coupled with a healthy dose of skepticism from trained clinicians who are rewarded for competency, not creativity in the delivery of health care, make design in medical institutions chal- lenging. The authors do a good job in preparing the designer for the task ahead.

On the negative side, the book can become tedious in terms of the number of case studies presented. Despite excellent descriptions of layout, accompanied by photographs of the sites, there is simply no substitute for being on-site and conducting one's own post-construction evaluation. The beauty of the book is that it allows one to do this, without the extensive background work that went into identifying the locations of various "healing gardens." The wise designer will use this information to begin building his/her own understanding of the attributes of site that are particularly important to various patient groups, and to visit these sites when there is an opportunity. As one begins to refine an understanding of the particular needs of a patient group in terms of threedimensional outdoor spaces, better design solutions will become a standard of practice in the industry.

Joanne M. Westphal is a landscape architect and licensed practicing physician in Michigan. She is an associate professor in the Landscape Architecture Program at Michigan State University in East Lansing. 